\title{
No Two Alike: Human Nature and Human Individuality
}

\author{
Judith Rich Harris \\ (2006).W.W. Norton \& Company, 322 pp, \$US26.95, ISBN 0393059480
}

We are all social beings by nature. That is what united the human species in our successful trip through evolution. But it is also the clue to explain human individuality, states Judith R. Harris in her second book, No Two Alike. After her first very successful book, The Nurture Assumption (1998), Harris in her second book sets out to disentangle how two genetically identical individuals who grow up in the same family, can turn out differently. How is it possible that they are perceived by themselves and by others as perfectly unique personalities? Harris takes the mask off the behavior geneticists' so-called 'nonshared environment'.

In the first half of the book, Harris offers an impressive review of theories and evidence presented by developmental psychology, behavioral genetics and evolutionary psychology, to explain nongenetic differences in personality. Harris proposes that children's personality is probably shaped as 'plastic' by evolutionary processes, so that they are able to adapt their behavior to circumstances in adult life. Although biological and environmental noise may cause some of the changes, the author insists that 'randomness is the explanation, or the excuse, that a scientist resorts to when all else fails' (p. 49).

Harris presents several 'red herrings' that have been proposed as explanations for nongenetic personality differences. Gene-environment interaction is the first. Although gene-environment interactions are relevant in understanding how genetically different people react differently to the same circumstances, they cannot explain differences between genetically identical individuals (i.e., monozygotic twins). Similarly, gene-environment correlations concern the way different genotypes drive people to different environments. Harris shows how a second critical look at apparently appealing research can reveal hidden methodological deficiencies that lead one to question the results. This is the case with Suomi's studies on cross-fostered monkeys, which claimed to demonstrate that nurturing mothers prevent their children from becoming aggressive.

Harris applies the same kind of skepticism to Frank Sulloway's publications concerning the effects of birth order on personality differences among siblings. Sulloway explained the differences between siblings as due to competition for resources within the home environment. The ease with which his theories spread through the scientific community and general public is related to the intuitive character of his claims. However, he insists on concealing his 'evidence'. Data from behavior genetic studies show that differences in parental behavior are a response to, and not a cause of, differences between siblings.

The first part of the book will fascinate readers of Twin Research and Human Genetics. Harris offers an excellent exhibition of complex reasoning and provides a comprehensive review of the literature, while making it understandable and enjoyable for the general public.

In the second half of her book Harris distils an overwhelming amount of evidence from a great variety of research fields, developmental, cognitive, social, and evolutionary psychology, neurophysiology, primatology, and even entomology. Step by step she builds upon her 'group socialization theory' outlined in The Nurture Assumption. She departs from the idea that behavioral consistencies are driven by genes, whereas the adaptive plasticity of behavior is driven by our ability to discriminate across different environments, and react differentially to them. This, translated into behavioral genetics terms, implies that the nonshared environment is responsible for the majority of personality changes that occur throughout the lifespan.

In the specification of the mechanisms that explain human individuality, Harris recovers the modular conception of the mind from evolutionary psychologists such as Steven Pinker, Leda Cosmides and John Tooby. She proposes that mental modules, similar to the ones that control vision or language, lead the two main social processes: socialization and personality development. The human species, as social beings, experiences two confronting tendencies: being accepted members of a group, and differentiating oneself from other members of the group. The socialization system drives the first tendency. Children observe the different behavior of people who belong to different social categories (e.g., males and females, adults and children). Their task in becoming socialized is to learn to which social categories they belong, and in which situations those categories apply. 
The relationship system drives our need to communicate and relate to other people. It stores information on each specific individual, and is responsible for our ability to make fine distinctions among them. Personality development, and therefore human individuality, is driven by the interaction between the relationship system and the status system. The status system drives our innate need to differ from others, to 'compete', to stand out as unique individuals within our group, or social category. We learn how to accomplish this goal by 'reading' what other people store in their relationship system about us. Even genetically identical twins are identified by others as different unique individuals, and the slightest difference between them (due, for example, to devel- opmental noise or random events), will be amplified by the feedback that they receive from other people's reactions.

The readers of Twin Research and Human Genetics may approach the second part with reservations. As the author says herself, scientists tend to specialize in a specific field of research and always view evidence through the same 'glasses'. Harris's theory is complex as it incorporates elements from a wide range of research fields. As with any complex theory, it not only appears hard to understand, but also difficult to test. But this does not mean impossible! In the last chapter of the book, the author proposes how certain features of the theory may be tested. There is no doubt that other explanations are possible for the personality differences between monozygotic twins. Epigenetic differences or the moderation of genetic expression by other environmental factors seem promising possibilities.

Yet again, Harris' writing is both inspiring and stimulating. With her ability to highlight the best and worst in every scientific work and her sharp style of reasoning and communicating, she provides the reader with unexpected views of the problem. No Two Alike will provoke less controversy than The Nurture Assumption, but will surely be the source of inspiration for new and creative research initiatives.

Irene Rebollo

Department of Biological Psychology, Vrije Universiteit, Amsterdam,

the Netherlands 